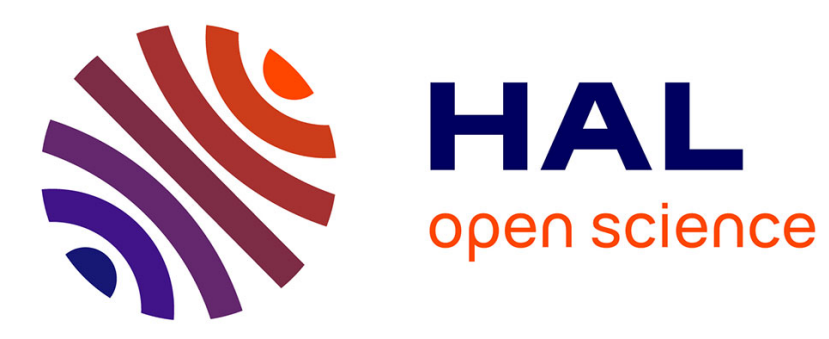

\title{
Infant diet and subcutaneous fat mass in early childhood. The Generation R Study
}

Vincent Jaddoe, Büşra Durmuş, Lamise Ay, Liesbeth Duijts, Henriëtte A

Moll, Anita Cs Hokken-Koelega, Hein Raat, Albert Hofman, E Steegers

\section{- To cite this version:}

Vincent Jaddoe, Büşra Durmuş, Lamise Ay, Liesbeth Duijts, Henriëtte A Moll, et al.. Infant diet and subcutaneous fat mass in early childhood. The Generation R Study. European Journal of Clinical Nutrition, 2011, 10.1038/ejcn.2011.174 . hal-00687021

\section{HAL Id: hal-00687021 \\ https://hal.science/hal-00687021}

Submitted on 12 Apr 2012

HAL is a multi-disciplinary open access archive for the deposit and dissemination of scientific research documents, whether they are published or not. The documents may come from teaching and research institutions in France or abroad, or from public or private research centers.
L'archive ouverte pluridisciplinaire HAL, est destinée au dépôt et à la diffusion de documents scientifiques de niveau recherche, publiés ou non, émanant des établissements d'enseignement et de recherche français ou étrangers, des laboratoires publics ou privés. 


\title{
Infant diet and subcutaneous fat mass in early childhood. The Generation R Study
}

Running title: infant diet and subcutaneous fat

\author{
Büşra Durmuş, $M S c^{1,2,3}$, Lamise Ay, $M D, \operatorname{PhD}^{1,2,3}$, Liesbeth Duijts, $M D, \operatorname{PhD}^{1,2,3}$, \\ Henriëtte A. Moll, MD, PhD ${ }^{2}$, Anita C.S. Hokken-Koelega, MD, PhD ${ }^{2}$, Hein Raat, MD, PhD ${ }^{4}$, \\ Albert Hofman, $\mathrm{MD}, \mathrm{PhD}^{3}$, Eric A.P. Steegers, $\mathrm{MD}, \mathrm{PhD}^{5}$, \\ Vincent W.V. Jaddoe, MD, $\mathrm{PhD}^{1,2,3}$ \\ ${ }^{1}$ The Generation R Study Group, Erasmus Medical Center, Rotterdam, \\ The Netherlands; \\ ${ }^{2}$ Department of Pediatrics, Erasmus Medical Center, Rotterdam, The Netherlands; \\ ${ }^{3}$ Department of Epidemiology, Erasmus Medical Center, Rotterdam, The Netherlands; \\ ${ }^{4}$ Department of Public Health, Erasmus Medical Center, Rotterdam, The Netherlands; \\ ${ }^{5}$ Department of Obstetrics and Gynecology, Erasmus Medical Center, Rotterdam, \\ The Netherlands.
}

\section{Correspondence:}

Dr. Vincent. W.V. Jaddoe, MD, PhD, The Generation R Study Group (AE-006), Erasmus Medical Center, PO Box 2040, 3000 CA Rotterdam, The Netherlands E-mail: v.jaddoe@erasmusmc.nl; Phone: +31107043405; Fax: +31107044645

Funding: The first phase of the Generation R Study is made possible by financial support from the Erasmus Medical Center, Rotterdam, the Erasmus University Rotterdam and the Netherlands Organization for Health Research and Development. The study sponsors had no role in study design, data analysis, interpretation of data, or writing this report. Vincent Jaddoe received an additional grant from the Netherlands Organization for Health Research and Development (ZonMw 90700303, 916.10159). Büşra Durmuş was supported by an unrestricted grant from Danone Research. 


\section{ABSTRACT}

2 Background: Breastfeeding has a protective effect on childhood obesity, but the influences

3 on body composition in early childhood are not known.

4 Objectives: To assess whether the duration and exclusiveness of breastfeeding, and the

5 timing of introduction of solid foods are associated with the subcutaneous fat mass in early

6 childhood.

7 Methods: This study was embedded in a population-based prospective cohort study among

8779 children. Peripheral (biceps, triceps) and central (suprailiacal and subscapular)

9 subcutaneous fat mass was measured as skinfold thickness at the ages of 1.5, 6 and 24

10 months.

11 Results: Breastfeeding duration was not associated with subcutaneous fat mass at the age

12 of 1.5 months. Shorter breastfeeding was associated with higher peripheral and total

13 subcutaneous fat mass at the age of 6 months ( $p$ value for trend $<0.05$ ), but not at the age of

1424 months. As compared to children who were exclusively breast fed for 4 months, those

15 who were non-exclusively breast fed had a higher central fat mass at the age of 24 months

16 ( $p$ value for trend $<0.01$ ). Timing of introduction of solid foods was not associated with

17 subcutaneous fat mass.

18 Conclusion: Our results suggest that a shorter duration and non-exclusive breastfeeding

19 affect early body composition during the first 2 years of life. Follow up studies at older ages

20 are needed to explore the long-term consequences.

Keywords: infant feeding, obesity, breastfeeding, solid foods, skinfold, pediatrics 


\section{INTRODUCTION}

Several studies showed a protective effect of breastfeeding on the risk of overweight in children and adults (Owen et al., 2005; Owen et al., 2005; Harder et al., 2005, Arenz et al., 2004). Although the effect estimates for the associations of breastfeeding with mean body mass index are generally small, they seem to be consistent (Owen et al., 2005; Owen et al., 2005; Harder et al., 2005; Arenz et al., 2004; Bergmann et al., 2003). An inverse dosedependent association has been shown, suggesting that longer duration of breastfeeding is associated with a lower body mass index (Harder et al., 2005; Arenz et al., 2004). Some studies have also suggested that early weaning may increase body mass index in childhood, but results are inconsistent (Wilson et al., 1998; Wright et al., 2004; Forsyth et al., 1993;

Morgan et al., 2004). Body mass index provides only information about body weight, whereas it does not distinguish between fat and lean mass (Wells and Fewtrell, 2006; Nevill et al., 2006). Since an unfavorable fat distribution may be stronger related to cardiovascular and metabolic diseases, it is important to explore the associations of breastfeeding with measures of fat distribution. Only a few studies have examined the relationships between breastfeeding in infancy and direct measures of adiposity in childhood, but no consistent associations were observed (Burdette et al., 2006; Gale et al., 2007). Skinfold thickness is a valid measurement for subcutaneous fat mass assessment in epidemiological studies (Wells and Fewtrell, 2006; Nevill et al., 2006). These measurements are quick and simple to obtain in most age groups, including young infants (Wells and Fewtrell, 2006). We have previously shown that birth weight is associated with subcutaneous fat mass in early childhood (Ay et al., 2009). Subcutaneous fat mass also tends to track throughout early childhood (Ay et al., 2009).

We examined in a population-based prospective cohort study among 779 children, the associations of breastfeeding duration and exclusivity, and timing of introduction of solid foods with peripheral, central and total subcutaneous fat mass in early childhood. 
METHODS

51

52

\section{Design}

This study was embedded in the Generation R Study, a population-based prospective cohort study of pregnant women and their children from fetal life onwards in Rotterdam, the Netherlands (Jaddoe et al., 2010). Enrollment in the study was aimed at early pregnancy (gestational age $<18$ weeks) but was possible until birth of the child. All children were born between April 2002 and January 2006, and form a prenatally enrolled birth-cohort that is currently followed until young adulthood. Additional detailed assessments of postnatal growth and development were conducted in a subgroup of 1106 Dutch mothers and their children from late pregnancy (Jaddoe et al., 2010). Between February 2003 and April 2005, all pregnant mothers participating in the Generation R study, who met this criterion, were approached for additional measurements (Jaddoe et al., 2010). Of all approached women, $80 \%$ agreed to participate in the subgroup study. The study protocol was approved by the Medical Ethical Committee of the Erasmus Medical Centre, Rotterdam. Written informed consent was obtained from all parents.

\section{Population for analysis}

From the total of 1106 children, 1039 children participated in at least one of the postnatal assessments at the ages of 1.5, 6 and 24 months (Figure 1). Children without complete information on breastfeeding $(n=225)$ were excluded from the analyses. Of the remaining 814 live births with complete data on breastfeeding, skinfold measurements were measured in at least one of the three visits in 799 children. Next, twins $(n=20)$ were excluded from the analyses since twins are correlated and may differ from other children in the relation between breastfeeding and subcutaneous fat mass. Missing skinfold measurements were mainly due to crying behavior. No differences in child and maternal characteristics were found between children with and without skinfold measurements $(n=779$ versus $n=1106)$. 
Information about breastfeeding initiation and continuation was obtained from delivery reports and postal questionnaires at the ages of 2, 6 and 12 months after birth, as previously described (Durmuş et al., 2011). Mothers were asked whether they ever breast fed their child

81 (yes; no) and at what age they quit breastfeeding. Subsequently, breastfeeding duration was categorized into three groups: 1) never; 2) less than 4 months; 3) 4 months or longer.

Duration of exclusive breastfeeding was defined by using information about at what age other types of milk and/or solids were introduced in the first 6 months of life, according to a short food frequency questionnaire. The information about duration and exclusiveness of breastfeeding was combined and categorized into the following three categories: 1) never; 2) non-exclusive breast fed until 4 months; and 3) exclusive breast fed until 4 months. Never indicates infants who were never breast fed. Non-exclusive indicates infants receiving both breastfeeding, and formula feeding or solids during the first four months. Exclusive indicates infants who have been breast fed, without any other milk, solids or fluids during the first four months. Information about timing of introduction solid foods like fruit- and vegetable snacks was obtained from the same short food frequency questionnaire. Starting solid foods was defined as the age that a fruit- or vegetable snack was given for the first time ( $<4$ months; 45 months; and > 5 months).

Subcutaneous fat mass measurements and anthropometrics

97 Subcutaneous fat mass was measured as skinfold thicknesses (SFT) in millimeters at the 98 ages of $1.5,6$ and 24 months on the left side of the body at four different sites (biceps, triceps, suprailiacal and subscapular) according to standard procedures by using a skinfold caliper (Slim Guide, Creative Health Products) (Lohman et al., 1991). Four well-trained medical assistants performed all measurements (WHO, 2006). The consensus between and

102 among observers for the medical assistants was analyzed using the intraclass correlation 103 coefficient (ICC) (Bland and Altman, 1986; Shrout and Fleiss, 1979). Intraobserver ICC was 1040.88 and interobserver ICC was 0.76 . Total subcutaneous fat mass was calculated from the 
sum of biceps SFT + triceps SFT + suprailiacal SFT + subscapular SFT. Central

subcutaneous fat mass was calculated from the sum of suprailiacal SFT + subscapular SFT.

107 Peripheral subcutaneous fat mass was calculated from the sum of triceps SFT + biceps SFT

108 (Ketel et al., 2007; Birmingham et al., 1993). Body length at the age of 1.5 and 6 months was

109 measured in supine position to the nearest millimeter using a neonatometer and in 24-month

110 olds height was measured in standing position by a Harpenden stadiometer (Holtain Limited,

111 Dyfed, U.K.). Weight was measured to the nearest grams in naked infants at the age of 1.5

112 and 6 months by using an electronic infant scale (SECA) and in 24-month olds by a

113 mechanical personal scale (SECA).

114

\section{Covariates}

116 Gestational age at birth, birth weight and sex were obtained from midwife and hospital

117 registries at birth. Information about highest attained maternal educational level and parity

118 were obtained at enrollment in the study. Educational level of the parents was defined

119 according to the classification of Statistics Netherlands (Statistics Netherlands, 2004).

120 Information on maternal smoking during pregnancy (yes; no) was retrieved from the prenatal

121 questionnaire. Maternal height and weight were measured at enrollment while the mother

122 stood without shoes and heavy clothing, and body mass index was calculated $\left(\mathrm{kg} / \mathrm{m}^{2}\right)$. 


\section{Statistical analysis}

124 Differences in baseline characteristics between the breastfeeding variables ever (never; ever), duration (< 4 months; $>4$ months) and exclusivity (non-exclusive breast fed until 4 months; exclusively breastfed until 4 months) were compared with Student's t-test for

127 continuous variables and Chi-square tests for categorical variables. The associations of

128 breastfeeding (never; ever), breastfeeding duration (never; $<4$ months; and $>4$ months),

129 breastfeeding exclusivity (never; non-exclusive until 4 months; and exclusive until 4 months),

130 and timing of introduction of fruit-and vegetable snacks ( $<4$ months; $4-5$ months; and $>5$

131 months) with peripheral, central, and total subcutaneous fat mass at the ages of 1.5, 6 and

13224 months, were assessed using multiple linear regression models. The reference groups of

133 these regression models were ever breast fed, breastfeeding duration of $>4$ months,

134 exclusive breast fed until 4 months, respectively. In these models, breastfeeding categories

135 were used as predictor variables and peripheral, central and total fat as outcome variables.

136 The models were adjusted for potential confounders including child's age at visit, sex,

137 maternal education, maternal body mass index, smoking and parity, gestational age, birth

138 weight, current height and observer. The models focused on the role of timing of introduction

139 of solid foods, were additionally adjusted for breastfeeding duration. Tests for trends were

140 performed by treating each categorized variable as a continuous term and by entering the

141 variable into the fully adjusted linear regression model. To handle missing values in

142 covariates, we performed multiple imputations by generating 5 independent datasets for all

143 analyses using the Markov Chain Monte Carlo method. Imputations were based on the

144 relationships between all covariates included in this study. All measures of association are

145 presented with their $95 \%$ confidence intervals $(\mathrm{Cl})$. Statistical analyses were performed using

146 the Statistical Package of Social Sciences version 17.0 for Windows (SPSS Inc., Chicago, IL, 147 USA). 


\section{Results}

152 Subject characteristics are given in Table 1. Of the total group of 779 children, $87.9 \%$ had

153 ever been breastfed with a mean duration of 4.5 months (range $0.5-12.0$ ). Differences

154 between the breastfeeding categories are given in the Supplementary material (Tables S1,

155 S2, S3). As compared to mothers who never breast fed their children, those who breast fed

156 their children had more frequently a higher educational level, were more likely to consume

157 alcohol during pregnancy but less likely to smoke (Table S1). Mothers who breast fed their

158 children for more than 4 months, compared to mothers who breast fed their children shorter

159 than 4 months, were older and had a lower body mass index (Table S2). Mothers who

160 exclusively breast fed their children had a lower weight, were more likely to have more than

161 one child and had children with a higher birth weight (Table S3).

162 The associations of ever breastfeeding, breastfeeding duration and exclusivity with

163 peripheral, central and total fat mass at the ages of 1.5, 6 and 24 months are shown in Table

164 2. Breastfeeding duration was not associated with subcutaneous fat mass at the age of 1.5

165 months. Shorter breastfeeding was associated with higher peripheral and total subcutaneous

166 fat mass at the age of 6 months ( $p$ value for trend <0.05), but not at the age of 24 months. As

167 compared to children who were breast fed exclusively for 4 months, those who were never

168 breast fed had a higher peripheral and total subcutaneous fat mass at the age of 6 months

169 and higher central fat mass at the age of 24 months ( $p$ value for trend $<0.01$ ).

$170 \quad$ Table 3 presents the associations between age at introduction of solid foods and

171 peripheral, central and total fat mass at the ages of $1.5,6$ and 24 months. As compared to

172 children who received solid foods after the age of 5 months, those receiving solid foods

173 before the age of 5 months, tended to have increased subcutaneous fat mass measures, but

174 these associations were not significant. 


\section{Main findings}

178 Results from this study suggest that a shorter duration and non-exclusive breast fed affect

179 early body composition during the first 2 years of life. A shorter duration of breastfeeding was

180 associated with higher peripheral and total subcutaneous fat mass at the age of 6 months,

181 whereas non-exclusive breast fed was associated with higher central subcutaneous fat mass

182 at the age 24 months. Early introduction of solid foods was not associated with subcutaneous

183 fat mass measures.

185 Strengths and weaknesses

186 The most important strengths of this study are the population-based prospective design with

187 a relatively large number of subjects being studied from early pregnancy onwards, and

188 information about a large number of potential confounders available. Our analyses were

189 based on 799 children with skinfold thickness measurements. Furthermore, information was

190 available about duration and exclusivity of breastfeeding. Some methodological issues need

191 to be considered. Of the total group of 1039 children, breastfeeding information was available

192 in $78 \%$. This non-response would lead to biased effect estimates if the associations of

193 breastfeeding duration and exclusivity with skinfold thickness measurements would be

194 different between those included and not included in the analyses. This seems unlikely

195 because biased estimates in cohort studies mainly arise from loss to follow-up rather than

196 from non-response at baseline (Nohr et al., 2006). Information about breastfeeding was

197 prospectively collected by questionnaires without direct reference to any skinfold

198 measurement. Although assessing breastfeeding by questionnaires seems to be a valid

199 method, misclassification may occur (Li et al., 2005). We estimated breastfeeding exclusivity

200 according to whether the child received breastfeeding without any other infant formula, milk

201 or solids according to the short food frequency questionnaire. This definition does not cover

202 the strict criteria used by the World Health Organization (WHO), which suggest that even the 
use of water in combination with breastfeeding does not fulfill the definition of exclusivity.

204 However, we did ask for the most commonly introduced solids and fluids. Furthermore, in

205 The Netherlands it is not common that children receive breastfeeding in combination with the

206 use of water to prevent dehydration. Therefore, we consider our measurement of exclusive

207 breast fed as a good proxy for exclusive breast fed according to the World Health

208 Organization criteria. Our definition of solid foods included only fruit or vegetable snacks.

209 However in the first months of life it is not likely that other products were introduced. We

210 created our specific duration, exclusivity and solid foods categories based on the collected

211 data and growth measurements. These categories do not enable direct comparison with the

212 widely used categories (6 months) of the WHO. Furthermore, our study group was ethnically

213 homogenous and the mothers were highly educated. We were not able to assess the effect

214 of breastfeeding on subcutaneous fat mass development in children with different ethnic and

215 social backgrounds. Finally, we used skinfold thickness as a measure of subcutaneous fat

216 mass because of the limited use of body mass index as a direct measure of adiposity in early

217 childhood. Skinfold thickness provide a simple, easy, and quick yet highly informative

218 assessment of regional fatness in most age groups and can be used in large-scale

219 epidemiological studies (Wells and Fewtrell, 2006). In general, intraobserver and

220 interobserver error are low compared to between-subject variability, but in obese children

221 accuracy and precision are poorer (Wells and Fewtrell, 2006; Nevill et al., 2006).

222 Furthermore, skinfold thickness has a limitation in assessing lean and fat mass of the whole

223 body (Wells and Fewtrell, 2006).

224

225 Comparison with other studies

226 Several studies have shown that breastfeeding is associated with a lower risk of later

227 overweight and obesity (Owen et al., 2005; Owen et al., 2005; Harder et al., 2005, Arenz et

228 al., 2004). Body mass index is a poor outcome due to its low predictive value and lack of

229 information about fat distribution (Wells et al., 2007). Studies focusing on the association

230 between breastfeeding and body composition instead of body mass index did show 
231 inconsistent associations (Burdette et al., 2006; Gale et al., 2007). This may be due to

232 differences in body measurements, ages and samples sizes. A study among adult males

233 from Brazil did not show an association between breastfeeding and adult body fat, measured

234 by skinfolds and fat mass using a bio-impedance scale (Victora et al., 2003), while a large

235 study in the UK reported a negligible protective effect of breastfeeding duration for more than

2366 months on mean body fat measured with Dual Energy X-ray Absorptiometry (DEXA) in

237 children aged 9-10 years (Toschke et al., 2007). Any association was attenuated after

238 adjustment for confounders. One study in Southampton reported a graded association

239 between shorter breastfeeding duration and higher DXA- derived fat mass in children aged 4

240 years (Robinson et al., 2009). In contrast, two studies, assessing the associations of

241 breastfeeding and direct measures of body composition using DEXA at ages of 2 and 5

242 years, did not show any association (Burdette et al., 2006; Tulldahl et al., 1999). We used

243 skinfold thickness as measures of subcutaneous fat mass at younger ages, but the results

244 are in line with these previous studies. Only at the age of 6 months we found that shorter

245 breastfeeding duration leads to higher peripheral and total fat mass. Our study was the first

246 study that used both breastfeeding duration and exclusivity, to examine the effect on

247 subcutaneous fat mass. We showed that non- exclusive breast fed was associated with

248 higher peripheral and total subcutaneous fat mass at the age of 1.5 months and higher

249 central fat mass at the age of 24 months. We cannot explain these differences. However,

250 central fat mass might be stronger related to adverse cardiovascular and metabolic health

251 outcomes (Fox et al., 2007; Pischon et al., 2008). Although the effect estimates were small,

252 exclusive breast fed might affect subcutaneous fat mass development in early childhood.

253 The European Society for Pediatric Gastroenterology, Hepatology and Nutrition

254 (ESPGHAN) Nutrition Committee recommended in 2008 that complementary foods (solid

255 foods and liquids other than breastfeeding or formula) should not be introduced before 4

256 months and not later than 6 months (Agostoni et al., 2008). Many studies in industrialized

257 countries showed non-adherence to these recommendations (Noble and Emmett, 2006;

258 Scott et al., 2009). In our Dutch study population, we found that most mothers introduced 
259 solid foods mainly after the age of 4 months. There is conflicting evidence about the relation

260 between timing of introduction of solid foods and adiposity in childhood. A few studies did not

261 show differences in adiposity between early and delayed introduction of solid foods (Kramer,

262 1981; Zive et al., 1992). One recent study suggested that a diet based on fruit, vegetables,

263 and home-prepared foods in the first year of life is associated with a higher lean and lower fat

264 mass measured with DXA at the age of 4 years (Robinson et al., 2009). The same study

265 group reported a greater gain in both weight and skinfold thickness between 6 and 12

266 months among infants who received the same diet with fruit, vegetables and home-prepared

267 foods at the age of 6 months (Baird et al., 2008). We did not observe significant associations

268 between early introduction of solid foods and subcutaneous fat mass measures.

269

270 Conclusion

271 Our results suggest that a shorter duration and non- exclusive breast fed affect early body

272 composition during the first 2 years of life. Early introduction of solid foods was not

273 associated with subcutaneous fat mass measures. Follow-up studies are needed to assess

274 whether breastfeeding duration and exclusivity affect subcutaneous fat mass and other

275 measures of body composition at older ages. 


\section{Acknowledgments}

278 The Generation R Study is conducted by the Erasmus Medical Center in close collaboration

279 with the School of Law and Faculty of Social Sciences of the Erasmus University Rotterdam,

280 the Municipal Health Service Rotterdam area, Rotterdam, the Rotterdam Homecare

281 Foundation, Rotterdam and the Stichting Trombosedienst and Artsenlaboratorium Rijnmond

282 (STAR), Rotterdam. We gratefully acknowledge the contribution of participating mothers,

283 general practitioners, hospitals, midwives and pharmacies in Rotterdam.

284

285 Conflict of interest

286 The authors declare no conflict of interest. 
Agostoni C, Decsi T, Fewtrell M, Goulet O, Kolacek S, Koletzko B et al; ESPGHAN Committee on Nutrition. (2008). Complementary feeding: a commentary by the ESPGHAN Committee on Nutrition. J Pediatr Gastroenterol Nutr 46, 99-110.

Arenz S, Rückerl R, Koletzko B, von Kries R (2004). Breast-feeding and childhood obesity--a systematic review. Int J Obes Relat Metab Disord 28, 1247-56.

Ay L, Van Houten VA, Steegers EA, Hofman A, Witteman JC, Jaddoe VW et al. (2009). Fetal and postnatal growth and body composition at 6 months of age. J Clin Endocrinol Metab 94, 202330 .

Ay L, Hokken-Koelega AC, Mook-Kanamori DO, Hofman A, Moll HA, Mackenbach JP et al. (2008). Tracking and determinants of subcutaneous fat mass in early childhood: the Generation $\mathrm{R}$ Study. Int J Obes (Lond) 32, 1050-9.

Baird J, Poole J, Robinson S, Marriott L, Godfrey K, Cooper C et al; Southampton Women's Survey Study Group. (2008). Milk feeding and dietary patterns predict weight and fat gains in infancy. Paediatr Perinat Epidemiol 22, 575-86.

Bergmann KE, Bergmann RL, Von Kries R, Böhm O, Richter R, Dudenhausen JW et al. (2003). Early

Birmingham B, Dyer AR, Shekelle RB, Stamler J (1993). Subscapular and triceps skinfold thicknesses, body mass index and cardiovascular risk factors in a cohort of middle-aged

Bland JM, Altman DG (1986). Statistical methods for assessing agreement between two methods of employed men. J Clin Epidemio/ 3, 289-302. clinical measurement. Lancet 1, 307-10.

312 Durmuş B, van Rossem L, Duijts L, Arends LR, Raat H, Moll HA et al. (2011). Breast-feeding and growth in children until the age of 3 years: the Generation R Study. Br J Nutr 31,1-9.

314 Forsyth JS, Ogston SA, Clark A, Florey CD, Howie PW (1993). Relation between early introduction of solid food to infants and their weight and illnesses during the first two years of life. BMJ $\mathbf{3 0 6}$, $1572-6$. 
317 Fox CS, Massaro JM, Hoffmann U, Pou KM, Maurovich-Horvat P, Liu CY et al. (2007). Abdominal

318 visceral and subcutaneous adipose tissue compartments: association with metabolic risk

319 factors in the Framingham Heart Study. Circulation 116, 39-48.

320 Gale CR, Javaid MK, Robinson SM, Law CM, Godfrey KM, Cooper C (2007). Maternal size in

321 pregnancy and body composition in children. J Clin Endocrinol Metab 92, 3904-11.

322 Harder T, Bergmann R, Kallischnigg G, Plagemann A (2005). Duration of breastfeeding and risk of

323 overweight: a meta-analysis. Am J of Epidemiol 163, 397-403.

324 Jaddoe VW, van Duijn CM, van der Heijden AJ, Mackenbach JP, Moll HA, Steegers EA et al. (2010).

325 The Generation R Study: design and cohort update 2010. Eur J Epidemiol 25, 823-41.

326 Ketel IJ, Volman MN, Seidell JC, Stehouwer CD, Twisk JW, Lambalk CB (2007). Superiority of

327 skinfold measurements and waist over waist-to-hip ratio for determination of body fat

328 distribution in a population-based cohort of Caucasian Dutch adults. Eur J Endocrinol 6, 655-

32961.

330 Kramer MS (1981). Do breast-feeding and delayed introduction of solid foods protect against

331 subsequent obesity? J Pediatr 98, 883-7.

332 Li R, Scanlon KS, Serdula MK (2005). The validity and reliability of maternal recall of breastfeeding

333 practice. Nutr Rev 63, 103-10.

334 Lohman TG, Roche AF, Martorell R (1991). Anthropometric Standardization Reference Manual:

$335 \quad$ Abridged Edition. Human Kinetics Books: Champaign, IL.

336 Morgan JB, Lucas A, Fewtrell MS (2004). Does weaning influence growth and health up to 18

337 months? Arch Dis Child. 89, 728-33.

338 Nevill AM, Stewart AD, Olds T, Holder R (2006). Relationship between adiposity and body size reveals

339 limitations of BMI. Am J Phys Anthropol 129, 151-6.

340 Noble S, Emmett $P$ (2006). Differences in weaning practice, food and nutrient intake between

341 breast- and formula-fed 4-month-old infants in England. J Hum Nutr Diet 19, 303-13.

342 Nohr EA, Frydenberg M, Henriksen TB, Olsen J (2006). Does low participation in cohort studies

$343 \quad$ induce bias? Epidemiology 17, 413-18.

344 Owen CG, Martin RM, Whincup PH, Davey-Smith G, Gillman MW, Cook DG (2005). The effect of

345 breastfeeding on mean body mass index throughout life: a quantitative review of published

346 and unpublished observational evidence. Am J Clin Nutr 82, 1298-1307. 
Owen CG, Martin RM, Whincup PH, Smith GD, Cook DG (2005). The effect of infant feeding on the risk of obesity across the life course: a quantitative review of published evidence. Pediatrics $115,1367-1377$.

Pischon T, Boeing H, Hoffmann K, Bergmann M, Schulze MB, Overvad K et al. (2008). General and abdominal adiposity and risk of death in Europe. N Engl J Med 359, 2105-2120.

Robinson SM, Marriott LD, Crozier SR, Harvey NC, Gale CR, Inskip HM et al; Southampton Women's Survey Study Group. (2009). Variations in infant feeding practice are associated with body composition in childhood: a prospective cohort study. J Clin Endocrinol Metab 94, 2799-805.

Scott JA, Binns CW, Graham KI, Oddy WH (2009). Predictors of the early introduction of solid foods in infants: results of a cohort study. BMC Pediatr 22, 9:60.

Shrout PE, Fleiss JL (1979). Intraclass correlations: uses in assessing rater reliability. Psychol Bull

Standaard onderwijsindeling 2003. (2004) Voorburg/ Heerlen: Statistics Netherlands.

Toschke AM, Martin RM, von Kries R, Wells J, Smith GD, Ness AR (2007). Infant feeding method and obesity: body mass index and dual-energy X-ray absorptiometry measurements at 9-10 y of

Tulldahl J, Pettersson K, Andersson SW, Hulthén L (1999). Mode of infant feeding and achieved growth in adolescence: early feeding patterns in relation to growth and body composition in

Wells JC, Fewtrell MS (2006). Measuring body composition. Arch Dis Child 91, 612-7.

Wells JC, Chomtho S, Fewtrell MS (2007). Programming of body composition by early growth and nutrition. Proc Nutr Soc 66, 423-34. in the WHO Multicentre Growth Reference Study. Acta Paediatr 450, 8-46. childhood health: seven year follow up of cohort of children in Dundee infant feeding study. 
BMJ 316, 21-5.

378 Wright CM, Parkinson KN, Drewett RF (2004). Why are babies weaned early? Data from a

379 prospective

380 population based cohort study. Arch Dis Child 89, 813-6.

381 Zive MM, McKay H, Frank-Spohrer GC, Broyles SL, Nelson JA, Nader PR (1992). Infant-feeding

382 practices and adiposity in 4-y-old Anglo- and Mexican-Americans. Am J Clin Nutr 55, 1104-8.

383 


\section{Legend for Figure 1}

Flow chart of participants in study 
Table 1 Subject characteristics ${ }^{a}$

$$
\begin{gathered}
\text { Total } \\
(n=779)
\end{gathered}
$$

\section{Maternal characteristics}

Age (years)

$32.3(24.9-37.9)$

Height (cm)

$170.8(6.3)$

Weight (kg)

$72.0(13.4)$

Body Mass Index $\left(\mathrm{kg} / \mathrm{m}^{2}\right)$

$24.7(4.4)$

Highest educational level (\%)

Low

1.8

Moderate

34.5

High

63.7

Smoking in pregnancy (\%)

Ever

22.2

Never

77.8

Alcohol consumption in pregnancy (\%)

Ever

70.1

Never

29.9

Parity (\%)

0

62.5

$\geq 1$

37.5

\section{Birth characteristics}

Males (\%)

51

Gestational age (weeks)

$40.3(37.1-42.1)$

Weight (grams)

3515 (549)

Small for gestational age $(<5 \%)$

4.9 
Low birth weight $(<2500 \mathrm{~g})(\%)$

Preterm birth (\%)

\section{Breastfeeding}

Ever (\%)

Duration (months)

\section{Solid foods (fruit- or vegetables)}

$<4$ months introduced (\%)

> 4-5 months introduced (\%)

$>5$ months introduced $(\%)$
3.6

4.1

87.5

$4.5(0.0-12.0)$

\section{7}

60.4

31.9

${ }^{a}$ Values are means (SD), percentages or medians (90\% range) for variables with skewed distribution. Of the total group, data were missing on maternal anthropometrics $(n=5)$, maternal education $(n=9)$, maternal smoking $(n=98)$, maternal alcohol use $(n=93)$, parity $(n=1)$, breastfeeding duration $(n=141)$, introduction solid foods $(n=153)$. 
Table 2 Associations of ever breastfeeding, breastfeeding duration and exclusivity of breastfeeding with subcutaneous skinfolds (mm) at different ages in early childhood ${ }^{\text {ab }}$

\begin{tabular}{|c|c|c|c|c|c|c|c|c|c|}
\hline & & Age 1.5 months & & & Age 6 months & & & Age 24 months & \\
\hline$N=779$ & $\begin{array}{l}\text { Peripheral fat } \\
\qquad(\mathrm{mm}) \\
(95 \% \mathrm{Cl})\end{array}$ & $\begin{array}{c}\text { Central fat } \\
\text { (mm) } \\
(95 \% \mathrm{Cl})\end{array}$ & $\begin{array}{c}\text { Total fat } \\
(\mathrm{mm}) \\
(95 \% \mathrm{Cl})\end{array}$ & $\begin{array}{c}\text { Peripheral fat } \\
\text { (mm) } \\
(95 \% \mathrm{Cl})\end{array}$ & $\begin{array}{l}\text { Central fat } \\
\qquad(\mathrm{mm}) \\
(95 \% \mathrm{Cl})\end{array}$ & $\begin{array}{c}\text { Total fat } \\
(\mathrm{mm}) \\
(95 \% \mathrm{Cl})\end{array}$ & $\begin{array}{l}\text { Peripheral fat } \\
\text { (mm) } \\
(95 \% \mathrm{Cl})\end{array}$ & $\begin{array}{c}\text { Central fat } \\
\qquad(\mathrm{mm}) \\
(95 \% \mathrm{Cl})\end{array}$ & $\begin{array}{c}\text { Total fat } \\
(\mathrm{mm}) \\
(95 \% \mathrm{Cl})\end{array}$ \\
\hline $\begin{array}{l}\text { Ever breast } \\
\text { fed }\end{array}$ & $N=653$ & $N=648$ & $N=648$ & $N=688$ & $N=686$ & $N=686$ & $N=584$ & $N=575$ & $N=575$ \\
\hline Never $(n=97)$ & $-0.24(-1.02,0.54)$ & $-0.22(-0.92,0.49)$ & $-0.45(-1.82,0.93)$ & $1.00(0.10,1.89)^{\star}$ & $0.25(-0.51,1.02)$ & $1.24(-0.22,2.70)$ & $0.23(-0.98,1.44)$ & $0.62(-0.34,1.57)$ & $0.86(-1.07,2.80)$ \\
\hline Ever $(n=682)$ & Reference & Reference & Reference & Reference & Reference & Reference & Reference & Reference & Reference \\
\hline $\begin{array}{l}\text { Duration of } \\
\text { being breast } \\
\text { fed }\end{array}$ & $N=615$ & $N=611$ & $N=611$ & $N=647$ & $N=645$ & $N=645$ & $N=553$ & $N=544$ & $N=544$ \\
\hline Never $(n=97)$ & $-0.16(-0.92,0.62)$ & $-0.12(-0.80,0.57)$ & $-0.26(-1.60,1.08)$ & $1.49(0.51,2.47)^{\star \star}$ & $0.50(-0.35,1.35)$ & $1.99(0.37,3.61)^{*}$ & $0.21(-1.13,1.55)$ & $0.90(-0.14,1.94)$ & $1.14(-0.98,3.26)$ \\
\hline $\begin{array}{l}<4 \text { months } \\
(\mathrm{n}=354)\end{array}$ & Reference & Reference & Reference & $0.69(0.02,1.37)^{\star}$ & $0.34(-0.24,0.92)$ & $1.04(-0.06,2.15)$ & $0.04(-0.82,0.91)$ & $0.50(-0.17,1.17)$ & $0.55(-0.82,1.92)$ \\
\hline $\begin{array}{l}>=4 \text { months } \\
(\mathrm{n}=283)\end{array}$ & N.A & N.A & N.A & Reference & Reference & Reference & Reference & Reference & Reference \\
\hline$P$ for trend & $P=0.38$ & $P=0.79$ & $P=0.50$ & $P<0.01$ & $P=0.18$ & $P=0.01$ & $P=0.79$ & $P=0.06$ & $P=0.26$ \\
\hline $\begin{array}{l}\text { Exclusive } \\
\text { breast fed }\end{array}$ & $N=653$ & $N=648$ & $N=648$ & $N=688$ & $N=686$ & $N=686$ & $N=584$ & $N=575$ & $N=575$ \\
\hline Never $(n=97)$ & $0.46(-0.43,1.35)$ & $0.14(-0.67,0.95)$ & $0.58(-0.99,2.15)$ & $1.40(0.37,2.42)^{\star \star}$ & $0.57(-0.30,1.44)$ & $1.96(0.29,3.63)^{\star}$ & $0.50(-0.86,1.86)$ & $1.24(0.17,2.30)^{\star}$ & $1.75(-0.42,3.91)$ \\
\hline $\begin{array}{l}\text { Non-exclusive } \\
\text { until } 4 \text { months } \\
(n=472)^{\mathrm{C}}\end{array}$ & $0.96(0.36,1.56)^{\star *}$ & $0.49(-0.05,1.04)$ & $1.42(0.36,2.48)^{\star \star}$ & $0.55(-0.14,1.24)$ & $0.44(-0.15,1.03)$ & $1.00(-0.13,2.12)$ & $0.37(-0.49,1.23)$ & $0.86(0.19,1.53)^{\star}$ & $1.23(-0.14,2.59)$ \\
\hline Exclusive until & Reference & Reference & Reference & Reference & Reference & Reference & Reference & Reference & Reference \\
\hline
\end{tabular}


${ }^{a}$ Values are unstandardized regression coefficients (95\% confidence interval).

${ }^{b *} P<0.05$ and ${ }^{* *} P<0.01$ using multiple linear regression models. Models are adjusted for child's age at visit, sex, birth weight, maternal education, maternal body mass index, smoking and parity, gestational age, current height and observer.

${ }^{c}$ Non-exclusive breastfeeding until 4 months includes partial until 4 months, partial thereafter; and partial until 4 months, not thereafter. Exclusive breastfeeding until 4 months includes exclusive until 6 months; exclusive until 4 months, partial thereafter; exclusive until 4 months, not thereafter. 
Table 3 Age at introduction of solid foods and subcutaneous skinfolds $(\mathrm{mm})$ in early childhood ${ }^{\text {a b c }}$

\begin{tabular}{|c|c|c|c|c|c|c|}
\hline Solid foods (fruit- or vegetables) & & Age 6 months & & & Age 24 months & \\
\hline \multirow[t]{2}{*}{$N=779$} & $\begin{array}{l}\text { Peripheral fat } \\
\qquad(\mathrm{mm}) \\
(95 \% \mathrm{Cl})\end{array}$ & $\begin{array}{l}\text { Central fat } \\
\qquad(\mathrm{mm}) \\
(95 \% \mathrm{Cl})\end{array}$ & $\begin{array}{l}\text { Total fat } \\
(\mathrm{mm}) \\
(95 \% \mathrm{Cl})\end{array}$ & $\begin{array}{l}\text { Peripheral fat } \\
\qquad(\mathrm{mm}) \\
(95 \% \mathrm{Cl})\end{array}$ & $\begin{array}{l}\text { Central fat } \\
\qquad(\mathrm{mm}) \\
(95 \% \mathrm{Cl})\end{array}$ & $\begin{array}{c}\text { Total fat } \\
(\mathrm{mm}) \\
(95 \% \mathrm{Cl})\end{array}$ \\
\hline & $N=486$ & $N=484$ & $N=484$ & $N=476$ & $N=469$ & $N=469$ \\
\hline$<4$ months $(n=48)$ & $0.23(-1.11,1.56)$ & $0.96(-0.30,2.21)$ & $1.18(-1.04,3.40)$ & $1.66(-0.11,3.42)$ & $-0.09(-1.39,1.21)$ & $1.29(-1.46,4.04)$ \\
\hline$>4-5$ months $(\mathrm{n}=378)$ & $-0.06(-0.79,0.67)$ & $0.45(-0.24,1.14)$ & $0.40(-0.82,1.61)$ & $0.82(-0.09,1.73)$ & $0.66(-0.01,1.33)$ & $1.46(0.05,2.88)^{*}$ \\
\hline$>5$ months $(n=200)$ & Reference & Reference & Reference & Reference & Reference & Reference \\
\hline$P$ for trend & $P=0.89$ & $P=0.10$ & $P=0.31$ & $P=0.03$ & $P=0.29$ & $P=0.08$ \\
\hline
\end{tabular}

${ }^{\mathrm{a}}$ Values are unstandardized regression coefficients (95\% confidence interval) using multiple linear regression models.

${ }^{\mathrm{b}}$ Models are adjusted for child's age at visit, sex, maternal education, maternal body mass index, smoking and parity, gestational age, birth weight, current height, observer and breastfeeding duration.

c * $P<0.05$ 

Figure 1 Flow chart of participants in study

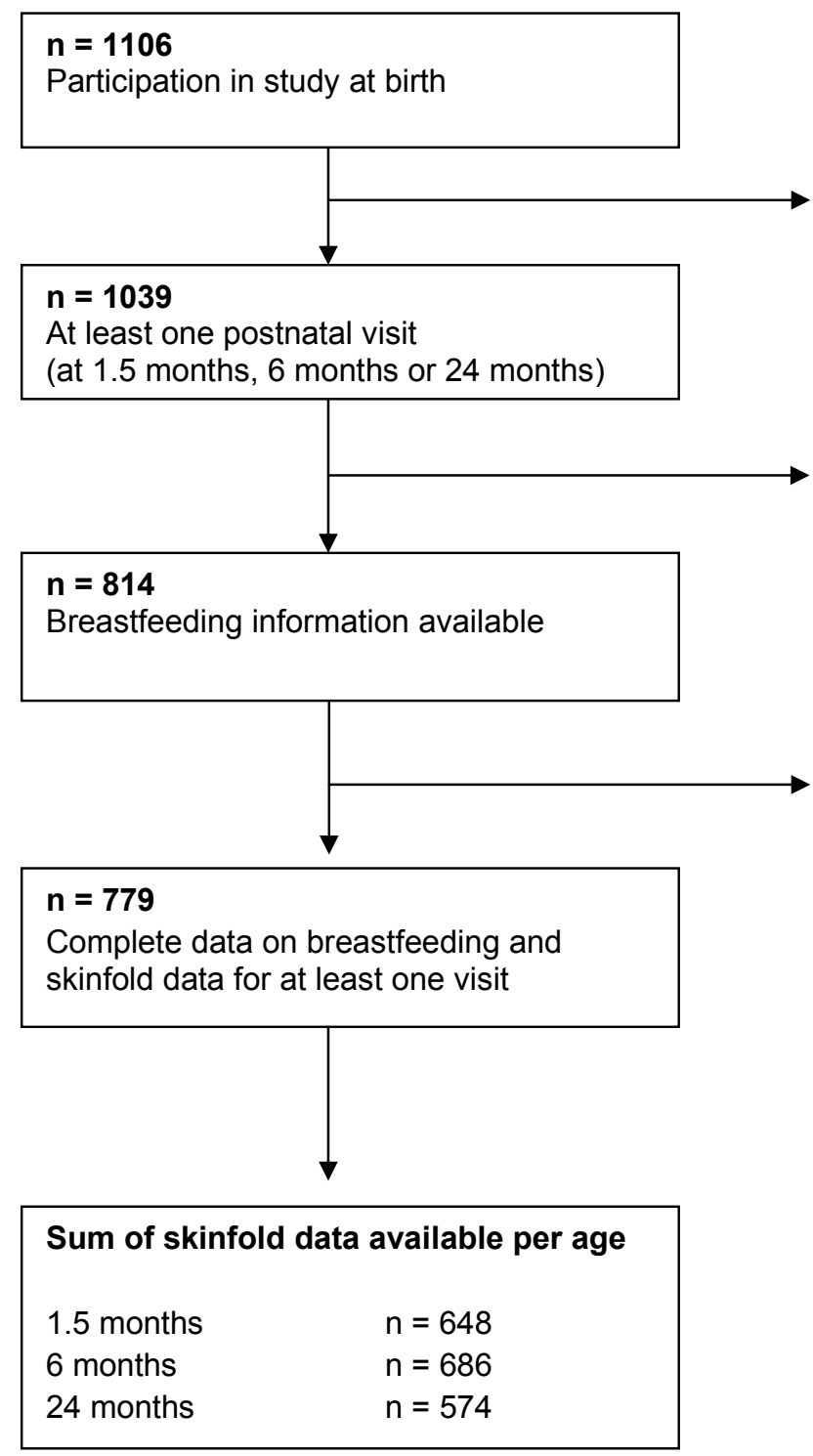

